MATEC Web of Conferences 53, 02002 (2016)

DOI: $10.1051 /$ matecconf $/ 20165302002$

(C) Owned by the authors, published by EDP Sciences, 2016

\title{
Orientational Reaction as a Way of Adjusting to Space
}

\author{
Ema Alihodzic Jasarovic ${ }^{1, a}$ and Rifat Alihodzic ${ }^{1}$ \\ ${ }^{1}$ Faculty of Architecture, University of Montenegro, 81 000, Podgorica
}

\begin{abstract}
This paper defines basic terms of movement and system of reference points in a city. We can conclude that primary difference in the perception of space and spatial orientation depends on the fact whether the subject lives in the city or he is a foreigner to that space. In this respect, we can conclude that when it comes to space orientation, foreigners mostly rely on visually and dimensionally strong and visible reference points, which can simultaneously be historical or morphological in terms of their character. On the one hand, the subject who is familiar with the area typically moves within a system of individual reference points. Individual system of reference points does not necessarily require any of the physical features that recommend an object as a reference point. On the other hand, there were numerous theories among which Lynch, after conducting a series of experiments related to space perception, pointed out that orientation depends solely on one's ability. Based on the analysis of the system of reference points, position of focus points and their relations, we can conclude that Podgorica, as most towns in Montenegro has a problem in terms of visual readability.
\end{abstract}

\section{Introduction}

Readability of a city image represents an ability through which a city could be seen as a whole which is made of several independent units and parts, indicating a physical clarity of the image [1]. Also, the entire landscape could be visually perceived as a complex composition of recognized symbols, which are used to identify certain parts of the city. The value of a city is measured by the amount of pleasure it can give to the persons who use it. It represents a need for a space that is suitable for people, in terms of its organisation that fits perceptive features of modern man. The role of the city image as a guide through space is very significant, because one gets to know and masters the space through movement. In accordance with this, the function of a visually well-organised surroundings is to facilitate movement. Also, the user of the space feels the constant need to be positioned and oriented, to create an image about their surroundings. The vividness does not necessary imply that the image of a city is apparent at first sight, or even noticeable and generally known or simple. A well-organised image of an urban surroundings is emphasised as the main precondition for using a city. Accordingly, discomfort resulting from a poor space organisation is not that uncommon. Kevin Lynch wrote about space recognition, noting that a city image has its value, not only by acting directly as a map used for orientation, but it also has a more general sense by serving as a general coordination system where individuals act or arrange their experiences and knowledge [1]. As a process of self-confirmation and self-determination in a space, orientation is just a segment in exploring possibilities of designing a space suitable for people.

${ }^{\mathrm{a}}$ Corresponding author : aema@t-com.me

This is an Open Access article distributed under the terms of the Creative Commons Attribution License 4.0, which permits unrestricted use, distribution, and reproduction in any medium, provided the original work is properly cited. 


\section{Movement and importance of a goal}

The topic of this paper is orientation of the subjects during their movement, their visual impressions when switching places, where dynamic characteristics are ascribed to the subject, in relation to the observed, immovable - static surroundings. Movement represents a change of position in a certain space during time, where perception of the movement cannot be perceived outside this context and that is when we are referring to a space spatiotemporality. By moving through space, one accomplishes a visual communication between the space user and the space itself, which mechanically presents a process that resulted from actions of visual forces. This paper deals exclusively with pedestrian movement, because every other type of movement would change the character and concept of the paper. Subject is the user of the space, he is its part, he goes through it, experiences and conquers it. The man, as a homo viator, is motivated with permanently movable and restless thinking [2]. At the beginning, it is necessary to make a difference between the subject who is a foreigner in a space, who does not have a defined starting point and who is not familiar with image of the city, and the one who lives in the city, and has a memory - mental image of the surroundings. That is why they have different perception of the city's image, distances, directions and proportions, and they use different ways for space orientation. Hodological space where the observer moves is usually, accidentally or potentially called a path, and it is always determined by forces that are created between the known and the unknown. Cornelia Faragode defined the path as non-place [2]. Christian NorbergShulz linked the path with one of the basic characteristics of human existence [3]. We always link direction with the path. Gordon Cullen described the space division of the beginning and the end through drama of space relations of what is "here" and what is "there" [4]. "Here" presents a static position of the observer, place - position of the current existence, where the being of the subject is defined as distance between presence and absence. In that case, the goal presents a focal point, to which we strive, a place of gathering, some type of a centre. Goal as a place of occupation, a focal point that we strive towards, affects the subject, motivates the movement and makes it focused. Therefore, the existence of a goal enables progress in movement and stimulates the state of expectation.

\section{Orientational reaction, disorientation}

In the process of movement, it is often not enough to define the starting point and the goal. Several different paths often lead to the same destination. Labyrinth, the old game of searching for the right path to the goal represents an example of path where only starting and finishing points are known. Such space without landmarks, leaves us without any support from the space and sensory signals that the surrounding sends. In the previous part, it was defined that the existence of a goal stimulates movement. On the other side, inexistence of forces of attraction and repulsion causes a panic because of the effect of objects' forces. Experiments were conducted in ideally artificial situation of laboratory labyrinth. Due to the lack of strong visual reference point, the interviewees reached for simple reference point like a gnarly board that they would recognize. In one such theory characterised by spatial divisions, differentiations, limitations, distances and demarcations, desert space succumbs to constant changes and unrecognisable paths, which leads to a limited and undirected movement. Accordingly, it could be concluded that orientation implies knowing our position in space and constant improvement of relations between us and the space. The lack of perceptual powers causes disorientation, which leads to fear and anxiety. Rudolf Arnheim stated that, in order to be successfully oriented, one must establish a number of markings in the exact timeframe and try to get a general insight that will show context and relations, alternatives, distances [5]. Disorientation is caused by a disturbed relation of perceptual powers owned by every object in space, to a greater or lesser degree. It could be caused by a collision of visual forces without any order, which makes it impossible to determine a place and spatial function of objects in the field of vision. This is most frequent in spaces that do not have a dominant space reference point whose visual forces are competitive to all of the structures built in space. 


\section{Space orientation reference systems}

View of a city is not constant, but fragmented, in order to accomplish clarity with which parts of the city can be recognised and organised in a whole. When a path has qualities such as direction or a defined and clear goal, we can talk about its proportion, and the space user could have a sense of how far has he gone and how much longer will it take to cross the path. Sense of proportion usually appears as a result of numerous famous markings along a path. In this case, we are referring to a subject that knows the locality and has a mental image of the city. When heading towards the goal, one conquers the path through stages, and by determining space in accordance with their personal sensibility. This way, subject form sections in their image which make short-term goals, and they always know where one phase of the path ends and another begins. Kevin Lynch introduced a term district [1], and Christian Norberg - Shulz mapped such points as places [3]. This way the path becomes a system of familiar point, where the trajectory becomes divided into a part before and after a point, i.e. what is behind and in front of us. This way, user of the space forms a system of individual reference points in relation to which they are oriented and which determine their homological space. Shulz believed that the entire person's space is centred subjectively and that every person's personal life has its centre [3]. As analogy to this, we can conclude that a foreigner cannot have a developed perception of the distance and sense of proportion in an unknown space, unless they have previous experiences and memories of that space. Unlike the subject that is familiar with the locality, a foreigner does not have a dimensional or temporal relation to the city. A foreigner does not know or feels the proportion. Those who visit the city for the first time form an impression based on the image that is experienced as a certain given thing. This impression is mostly unbiased, unburdened by those emotional elements that local residents have. As such, it can be very realistic in evaluation of the quality of spatial relations. A foreigner needs a readable image in order to get around in space more efficiently. That image is formed as an abstract and simplified system of visual references. It demands a strong visual reference point - a visual and spatial identification, in order for their movement to be clearly directed towards the goal [6].

Exploration and determination of the reference point system of a city analytically digs deeply into the zone of urban and spatial relations, architectural compositions and its elements from the aspect of perception, as well as personal abilities of the subject - participant in the space [7]. When writing about the ways of orientation, Arnheim pointed out that the subject is very frequently oriented in relation to the street [5]. He believes that buildings are parts of sequences and they barely express their three-dimensional quality in that structure. Figural character formed by walls of the buildings is the dominant characteristic of spatial actions. This is even more visible when driving a car, where the increased speed accentuates penetration into empty space and focuses attention on what is happening within that space. It should be pointed out that the character of the street is greatly affected by its width and height of the objects that form it. Only in the case of well-positioned height and width proportions, street could be established as a visual object with its personal visual centre, which actively resists forces that come from the buildings that form it. In many streets, orientation points cannot be recognised, and the streets do not have a figural character that was previously discussed, because the centres of visual balance were disturbed due to reckless setting of objects and their mutual relations. It points to a fact that a street, in terms of design, should provide expressive properties that state direction, in order to enable easier orientation and movements through space $[8,9]$.

Sometimes the image of surroundings is not organised by a system of dominant directions, but through one or more foci, which are used to measure distances and determine directions. These reference points also include morphological reference points such as mountains, rivers, hills... Urban planning of Podgorica is determined in relation to two rivers, which divide it into three clearly defined zones: Stara Varoš, Nova Varoš and Novi grad. The river represents an important spatial reference point within this spatial organisation.

One of the most common ways of orientation is finding previously imposed, adopted and already known reference points, which are usually historical reference points. The first contact with an unfamiliar city includes spatial orientation and positioning. We do this by locating things in relation to already familiar city points. Since we are strangers, we do not have earlier spatial experiences related 
to that place and so we reach for information related to those areas or buildings in the city which represent its landmarks and which we use to recognise that place. They become our zero -starting point, from which we perceive the city image. Landmarks such as specific buildings, especially those important for the city, towers or sculptures, squares and bridges, they all help to determine the reference points and emphasize the hierarchy of places. The Fig. 1 shows Acropolis (a strong morphological and visual reference point) and Eiffel tower (historical and visual reference point).
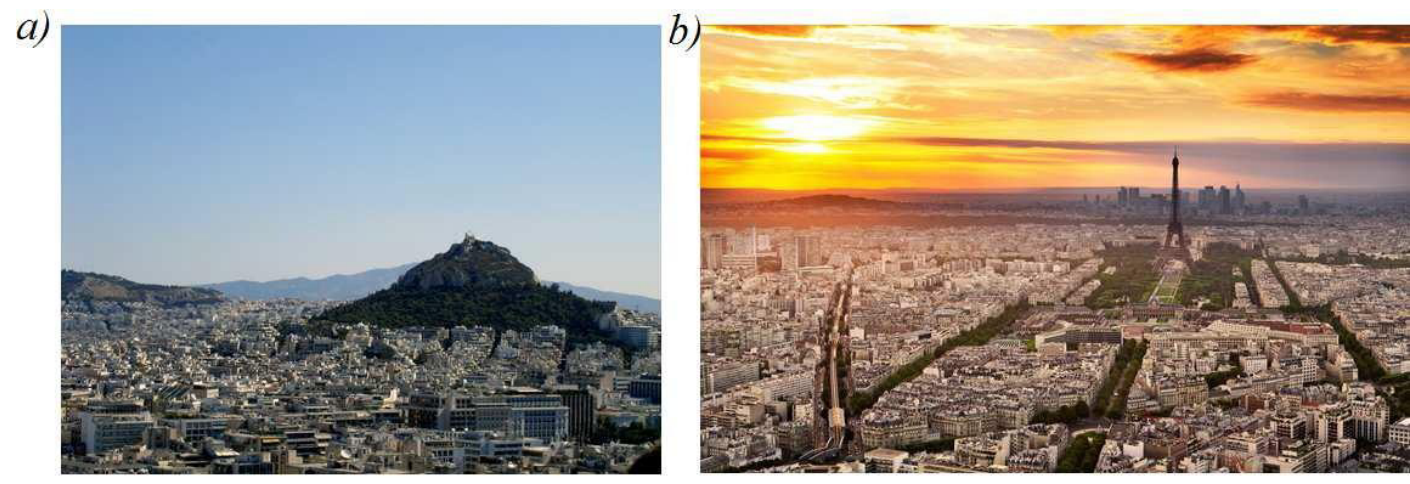

Figure 1. a) Acropolis; b) Eiffel tower.

For example, when we arrive in Paris for the first time, the first thing we look for is the Eiffel tower, a historical, architectural, monumental symbol which we will use to position ourselves in space, and it will become our main orientation and reference point as well as a starting point for any further movement, orientation and reconnaissance of space. This is how we come to a situation where we determine a place by using a building, by forming limited areas which make that place distinctive. From the analytical point of view of perception, Rudolf Arnheim considers these places as a basis for dynamic action [5]. He points out that in a dynamic sense, a tower which stands in an empty field or a ceramic vase on a table represent centres of visual energy which transmit vectors in all directions. However, it is very rare that a building is alone in an empty space. Usually, the building is in touch with the surroundings and neighbouring buildings which also have vector forces that affect each other, influence the observer's eye and disrupt the centricity of the composition. Therefore, every spatial composition represents a configuration of forces of perception, and the reference point's task is to overcome competitive vector forces and become dominant. This visually dominant position in space represents a feature of visually distinctive buildings which are easily recognised in space [10].

In the previous section we have repeatedly emphasized the importance of space that is suitable for people, it terms of its physical and visual identification, which enables easy movement and orientation, and makes the city image easy to perceive. A survey was performed as a part of this paper and it included citizens of Montenegro, coming from different urban structures and city's levels of development. When asked what is the reference point of a city, most of the participants of different age and education structure connected that characteristic place with a place where they meet, which they use for orientation and to locate other places of lesser significance. In most case, this was not a high and dimensionally strong benchmark, but instead their answers often included fountains, bridges, monuments, rivers, parks, squares, stations, benches, stairs, shops, advertisements. They often pointed out the place of residence, a house, as a focus point and explained that this represented a place which they left and returned to on a daily basis. In the given moment, they located their position in relation to the strongest reference point they listed. When doing this, interviewees demonstrated good knowledge of dimensions, distances, scale and often added time dimension to describe the distance from the benchmark, thus indicating experiential category. We can conclude that every interviewee had an individual system of reference points in which he moved and functioned. In the previous part of the term paper it was pointed out that when it comes to a person who knows the city, the orientation 
system was usually reduced to an individual system of reference points. In terms of perception, these points can be completely unexpected things which do not have an important role in the overall townscape $[7,8]$.

\section{Physical characteristics of reference points}

By analysing physical characteristics of buildings that may become potential visual reference points in an area, we can conclude that one of the most significant features is the dimension of the building. When it comes to architectural composition and its elements in terms of perception, the spiritual component of human aspiration towards God is most easily accepted as something that bears an individual shaping of distinct dominance in pure nature. Such forms are easily perceived by a human eye, and they are accepted as accents, landmarks and signposts. Organisation with the help of these reference points proved to be very useful in practice. It also creates an environment which is easy to perceive [11-13]. With their elevation above the uniform structures, the silhouette of high structures can be used to highlight key locations. This type of orientation bears a risk of losing the reference point in case the position or distance is changed, because we perceive things from different points. We often notice a reference point from a large distance and start moving towards it, or we orient in relation to that point. The problem occurs when we go inside the city and lose the sight of the reference point because of the visual influences from the surrounding buildings, which "block" the reference point. In this way, it loses its spatial role in the city's system of reference points [14]. All this indicates another important category which implies the importance of positioning of a reference point within an urban area as well as a constant road tracing and opening of vistas towards the focus point. The Fig. 2 shows Obelisk, (Washington) - a strong and dimensional reference point and Egyptian pyramids - purity of shapes.
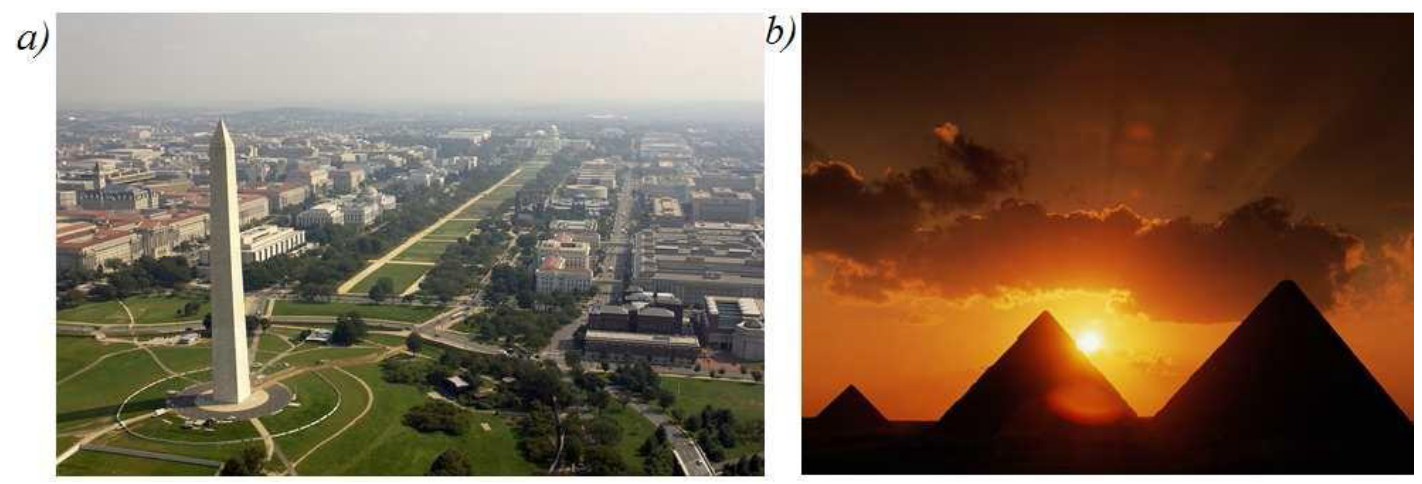

Figure 2. a) Obelisk, Washington; b) Egyptian pyramids.

In addition to the height characteristic, shape component represents a prominent feature of a reference point. In this case we are talking about individuality of an object which stands out by being different, and aims to make the object easier to remember and find. This is where we leave the primary area of readiness to receive stimuli, and move to a higher level of remembering and association processes. When it comes to a visual experience of the architectural form in terms of perception, we can conclude that visually strong, dynamic and aggressive objects are key for perception of a certain urban image. Lynch notes that the object is also more remarkable if it has a clarity of general form, as does a column or a sphere [1]. 
Another important category in terms of readability of reference points is the quantity - frequency of reference points in a certain area. Sometimes it is enough to have one reference point which has a good position in terms of dimension, shape and space in order to make a space an easily perceivable surrounding, which will be easy to orient and move. On the other hand, to many reference points can easily create a visual imbalance, due to a disturbed relations between forces possessed by every object in space. In the spatial concept of megacities, the position of reference points becomes compacted and frequent, thus losing this effect (Fig. 3). These cities do not have suitability of space, they disturb every sense of size and scale, and the subject sets for himself a new, suitable system of reference points for orientation $[14,15]$.

Figure 3. Saturation with visual reference points New York [10].

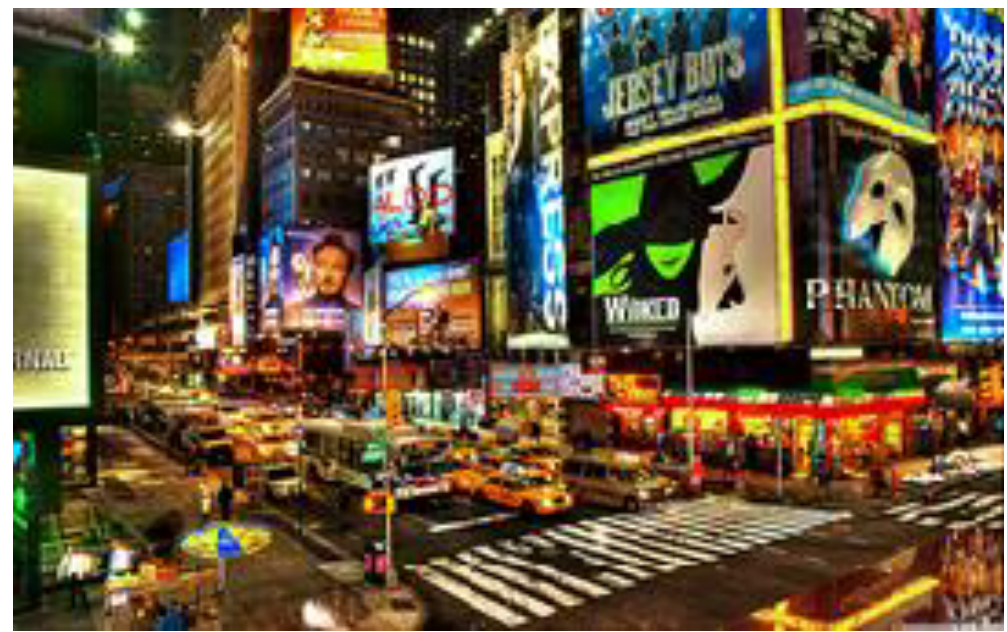

The principle of perception of an object stands out in further analysis of features that suggest an object as a reference point of a city. Here, an important role is played by a principle of figure and background, where dynamic features of the background do not make it passive. It can accentuate the object or completely diminish its visual effect and power [16]. Therefore, the position of the reference point in relation to the background represents is a very important principle. Its role is to favour the figure by keeping it the foreground. The Fig. 4 shows Istanbul skyscrapers which disturb the vista over the most famous city reference point and simplicity principle [6].
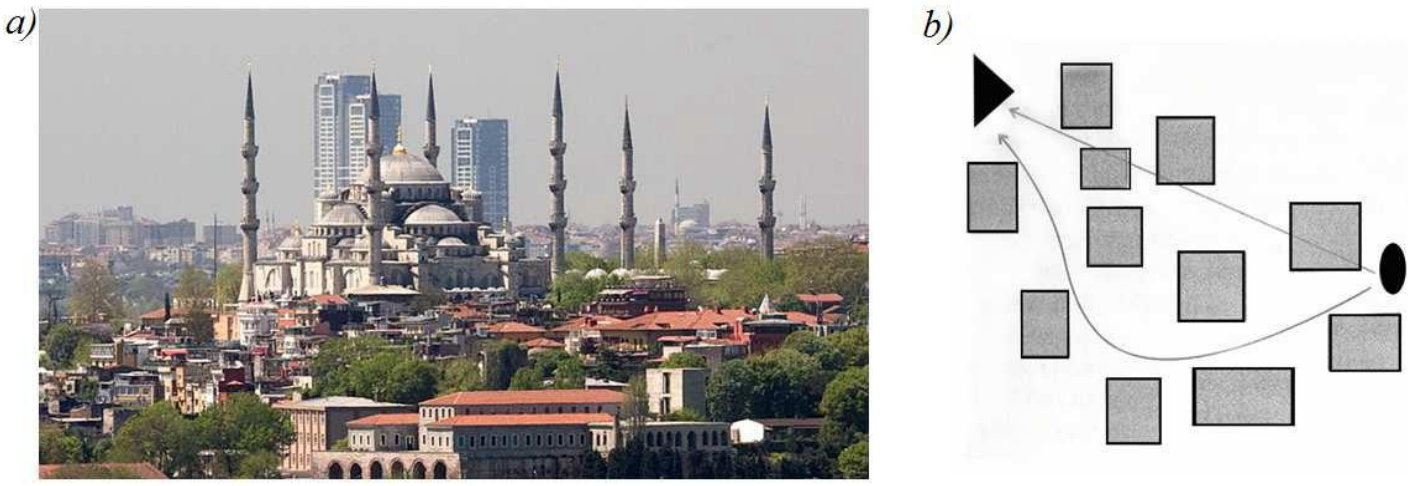

Figure 4. a) Istanbul; a) Simplicity principle.

Another gestalt principle of perception includes the principle of simplicity, which explains that a person functions in a three-dimensional space in every given moment. When walking towards an element which has emerged as a focus, our spatial relation remains a straight line despite the fact that 
there are numerous buildings between us and the reference point [17, 18]. This difference between the mental and real image of the city can often cause confusion or disorientation.

\section{Summary}

The dynamics of composition, vibrancy and coherence of the urbane image is emphasized as a central and main condition for the use of a city, because the user of a space seeks for a visual drama and not only a gallery of moving images. It is also important to emphasize that we orient by remembering a series of distinct details. There are undeniable benefits from spending time in an enriched environment in terms of harmonious development of person's sphere of psychological knowledge. In addition to its function in movement and orientation, the importance of the system of reference points in the image of a city is that it can significantly contribute to the visual identity of a space. Visual identity of the urban image is desirable and it can contribute to achieving a balanced relation between its global recognisability and local authenticity [9].

\section{References}

1. K. Lynch, Image of the City, (DTB, Belgrade, (1974)

2. K. Farago, K. Dynamics of space, movement places, (DTB, Belgrade, 2007)

3. K. N. Sulc, Existence, space and architecture, (DTB, Belgrade, 2002)

4. G. Cullen, City landscape, (DTB, Belgrade, 1990)

5. R. Arnhajm, Dynamics architetectural form, (DTB, Belgrade, 1995)

6. Information from: http://gorkorg.blogspot.co.uk/ (26.12.2015)

7. R. Alihodzic, Defining the primary aspects of psychological experience of architectural space and form, (Ulcinj, 2007)

8. R. Alihodzic, V. Murgul, N. Vatin, Applied Mechanics and Materials, 680, 494-498 (2014)

9. G. Radovic, V. Murgul, N.I. Vatin, Applied Mechanics and Materials, 584-586, 564-569 (2014)

10. S. Popović, N. Djurovic, V. Murgul, Procedia Engineering, 117, 832-840 (2015)

11. G. Radovic, V. Murgul, N. Vatin, Applied Mechanics and Materials, 641-642, 634-638 (2014)

12. I. Yamshanov, V. Goryunov, V. Murgul, Procedia Engineering, 117, 675-684 (2015)

13. I. Zayats, V. Murgul, Procedia Engineering, 117, 706-711 (2015)

14. Y. Nikitin, V. Goryunov, V. Murgul, N. Vatin, Applied Mechanics and Materials, 680, 504-509 (2014)

15. V. Goryunov, I. Zayats, T. Konjkova, V. Murgul, Procedia Engineering, 117, 825-831 (2015)

16. V. Murgul, N. Vatin, I. Zayats, Procedia Engineering, 117, 824-829 (2015)

17. I. Yamshanov, V. Goryunov, V, Murgul, Procedia Engineering, 117, 663-674 (2015)

18. Noth, M., Borning, A., Waddell, P. Computers, Environment and Urban Systems, 27(2), 181203, (2003) 